Special issue of the 3rd International Conference on Computational and Experimental Science and Engineering (ICCESEN 2016)

\title{
Effects of the Nanoclay and Intumescent System on the Properties of the Plasticized Polylactic Acid
}

\author{
S. HAZER ${ }^{a}$, M. $\operatorname{COBAN}^{a}$ AND A. $\operatorname{AYTAC}^{a, b, *}$ \\ ${ }^{a}$ Kocaeli University, Chemical Engineering Department, Kocaeli, Turkey \\ ${ }^{b}$ Polymer Science and Technology Department, University of Kocaeli, Turkey
}

\begin{abstract}
The aim of this study is the investigation of the effects of an intumescent system, consisting of ammonium polyphosphate (APP), as a flame retardant additive, pentaerythritol (PER), as a carbonic agent, and nanoclay, as a synergistic agent, on the flame retardancy of plasticized poly(lactic acid) (PLA). In accordance with this purpose, plasticized and flame retarded PLA with APP compound was prepared and used as a control sample. Nanoclay loading levels were changed between 3 and $10 \mathrm{wt} \%$ in the PLA/APP/PER samples. Samples were produced using extrusion and injection molding techniques. The morphological, thermal, mechanical and flammability properties were studied. The flammability evaluation was performed using limiting oxygen index and vertical burning (UL-94) tests. The obtained limiting oxygen index value was up to 32.9 and UL-94 grade could pass V-0 for samples, containing $3 \mathrm{wt} \%$ of nanoclay. However, increasing nanoclay amount has enhanced the burning time of the sample. The thermal behaviors of the samples were characterized by differential scanning calorimetry. It was shown, that PER incorporation did not significantly change the percentage crystallinity value. The increasing nanoclay loading levels reduced the degree of crystallization. Elongation at break value of sample, containing 5 wt. $\%$ of nanoclay, increased by $28 \%$, compared to the control sample.
\end{abstract}

DOI: 10.12693/APhysPolA.132.634

PACS/topics: 81.05.lg, 81.05.qk, 82.35.np

\section{Introduction}

Biodegradable polymers draw attention due to environmental issues of petroleum-based plastics. Among the biodegradable polymers, poly(lactic acid) (PLA) has received an increasing amount of attention from both academy and industry, because it is produced by fermentation from renewable resources, such as corn or sugar beet [1]. Compostable and biodegradable properties of PLA provide useful solution to solid waste management problems [2]. PLA is a linear, semicystalline, aliphatic, biodegradable polyester, which is also mostly plasticized before using, in order to increase its ductility. Poly(ethylene glycol) (PEG) is the most used plasticizer for PLA [2-3]. PLA is a promising material for replacing some petro-chemical polymers, due to its excellent mechanical properties and high degree of transparency [1].

PLA has found a great usage area in different industries. Kimura et al. reported that PLA can be used for housings of portable word processors, so their study points out at PLA-based materials, which have a great potential in electronics applications. On the other hand high combustibility and melt dripping nature of PLA restricts its applications in electronic, electrical and automotive industries [4]. Therefore, having flame retardancy becomes an important requirement for PLA, at this point.

Fire retardant materials are classified as halogen, phosphorous, nitrogen and inorganic compounds [5].

*corresponding author; e-mail: aaytac@kocaeli.edu.tr
In earlier studies, various materials, such as ammonium phosphate, melamine phosphate and halogen-containing compounds were used as a flame retardants in PLA, to improve its flame retardancy. Halogenated organic compounds cause serious environmental problems and human hazard due to release of halogen acids and some high toxic products during combustion [6].

Another way to improve flame retardancy of the polymers is to use intumescence flame retardant system (IFR) [7]. IFR systems are known as effective flame retardants and are used in many polymers [8-9]. The system generally consists of three components: an acid source, a carbonization agent, and a blowing agent [10-11].

In literature there are studies focused on synergetic effects of APP and PER in PLA matrix, however there are no studies on APP/PER/nanoclay system for plasticized PLA. Réti et al. evaluated the efficiency of different intumescent formulations as flame retardant for PLA [10]. The best limiting oxygen index (LOI) value and the lowest heat release rate (HRR) peak were obtained for the formulation containing APP and PER. This formulation exhibits a V-2 classification in the UL-94 test.

Another study has shown that the IFR system containing hyperbranched polyamine charring agent (HPCA) and APP indicates high efficiency for increasing flame retardant and anti-dripping properties of PLA [6]. Zhu et al. introduced APP and expandable graphite (EG) into PLA to improve its flame retardancy properties and efficiency. Synergistic flame retarding effect between APP and EG was observed in PLA matrix. LOI value of 36.5 and UL-94 V-0 rating was reached for PLA with 15 wt.\% IFR content [12]. 
Pluta et al. studied the thermal and morphological properties of the PLA-based organoclay nanocomposites [13]. The study indicated an improvement in the nanocomposite thermal stability under oxidative conditions, compared to unfilled PLA.

In this study, the effect of nanoclay on the APP/PER intumescent system in plasticized PLA was investigated. Various ratios of nanoclay were added to IFR-containing PLA. Thermal, mechanical and burning behaviour of the samples was investigated for observing the synergic effect of nanoclay and IFR system.

\section{Materials and methods}

\subsection{Materials}

Poly(lactic acid) (PLA) (PLI005, MFI: 5-7 g/10 min $190^{\circ} \mathrm{C}, 2.16 \mathrm{~kg}$ ), kindly supplied from Natureplast, was used as the matrix material with plasticizer PEG(polyethylene glycol). PEG $\left(M_{w}: \sim 8000\right)$ was obtained from Aldrich. APP (ammonium polyphosphate) (Mileflame APP 201) was used as flame retardant. Nanoclay was supplied from ESAN Eczacıbaşı. Pentaerythritol (PER) was supplied from MKS Marmara.

\subsection{Sample preparation}

PLA and nanoclay were dried in a vacuum oven at $80^{\circ} \mathrm{C}$ for 12 hours and at $50^{\circ} \mathrm{C}$ for 12 hours, respectively, before the composite preparation process. All composites were compounded in a laboratory scale co-rotating twin-screw mini extruder (DSM Xplore 15ml Microcompounder) at $200^{\circ} \mathrm{C}$ for 3 min under screw speed of $100 \mathrm{rpm}$. Compounding weight ratios of samples are provided in Table I. Samples were subsequently injection molded by using a laboratory scale injection molding machine with a barrel temperature of $200^{\circ} \mathrm{C}$, under injection pressure of 10 bar.

TABLE I

Compounding ratios of samples.

\begin{tabular}{c|c|c}
\hline \hline & Samples & $\begin{array}{c}\text { Weight } \% \text { fractions } \\
\text { of the compounds }\end{array}$ \\
\hline 1 & PLA/PEG & $90 / 10$ \\
2 & PLA/PEG/APP & $72 / 8 / 20$ \\
4 & $\mathrm{PLA} / \mathrm{PEG} / \mathrm{APP} / \mathrm{PER}$ & $72 / 8 / 15 / 5$ \\
5 & $\mathrm{PLA} / \mathrm{PEG} / \mathrm{APP} / \mathrm{PER} / 3 \mathrm{NC}$ & $72 / 8 / 12.75 / 4.25 / 3$ \\
6 & $\mathrm{PLA} / \mathrm{PEG} / \mathrm{APP} / \mathrm{PER} / 5 \mathrm{NC}$ & $72 / 8 / 11.25 / 3.75 / 5$ \\
7 & $\mathrm{PLA} / \mathrm{PEG} / \mathrm{APP} / \mathrm{PER} / 10 \mathrm{NC}$ & $72 / 8 / 7.5 / 2.5 / 10$
\end{tabular}

\subsection{Characterization}

Tensile properties of composites were measured by using Instron universal testing machine, according to ISO $5275 \mathrm{~A}$ standards. The dimensions, of the test samples were $4 \mathrm{~mm}$ width, $2.10 \mathrm{~mm}$ thickness and $30 \mathrm{~mm}$ length. The crosshead speed was $5 \mathrm{~mm} / \mathrm{min}$. Five specimens from each group were tested and an average values of each group were reported with standard deviations.
Differential scanning calorimetry (DSC) analysis was performed using Mettler Toledo DSC 1 apparatus, under nitrogen atmosphere. The samples were heated from $25^{\circ} \mathrm{C}$ to $200^{\circ} \mathrm{C}$ at a heating rate of $10^{\circ} \mathrm{C} \mathrm{min}^{-1}$ and held at that temperature for $5 \mathrm{~min}$. Then samples were cooled from $200^{\circ} \mathrm{C}$ to $25^{\circ} \mathrm{C}$ at a cooling rate of $10^{\circ} \mathrm{C} \mathrm{min}{ }^{-1}$. The degree of crystallinity values of composites were calculated according to thermal properties of PLA. Heat of fusion of PLA was assumed to be $93.5 \mathrm{~J} / \mathrm{g}$ [14].

Thermogravimetric analysis (TGA) was performed in Metler Toledo TGA Star trademark machine under nitrogen atmosphere. Samples were heated in the range from $25^{\circ} \mathrm{C}$ to $800^{\circ} \mathrm{C}$ at a heating rate of $10^{\circ} \mathrm{Cmin}^{-1}$.

Limiting oxygen index (LOI) values of the samples were measured using Mares Analysis Instrument oxygen meter (M-LOI-01) according to the ISO 4589-2 standard. The sample with a mark at $50 \mathrm{~mm}$ was held vertically in the transparent chimney, where the flows of oxygen and nitrogen were controlled. The fact, whether the burning length passes $50 \mathrm{~mm}$ limit or not, was reported. The LOI tests were repeated under different concentrations of oxygen and nitrogen to determine the minimum concentration of oxygen needed for sample burning.

The UL-94 vertical burning test was performed on the vertical burning test instrument, according to the ASTM D3801 testing procedure. The samples were moulded as rectangular samples with dimensions of $80 \times 10$ $\times 4.0 \mathrm{~mm}^{3}$.

Morphological investigations of the fractured samples were done by using scanning electron microscope (SEM) (JOEL JSM 6510).

\section{Results and discussion}

\subsection{Mechanical characteristics}

Tensile strength and strain values of composites were obtained from tensile tests. The tensile strength values of the samples are illustrated in Fig. 1. Figure 1 shows that the addition of APP has increased the tensile strength value of PLA/PEG and the maximum measured tensile strength value for PLA/PEG/APP sample was 39.2 MPa. Besides, the tensile strength values of the samples have decreased with the addition of nanoclay and carbonic agent (PER). In addition to this, increasing nanoclay content has decreased further the tensile strength values.

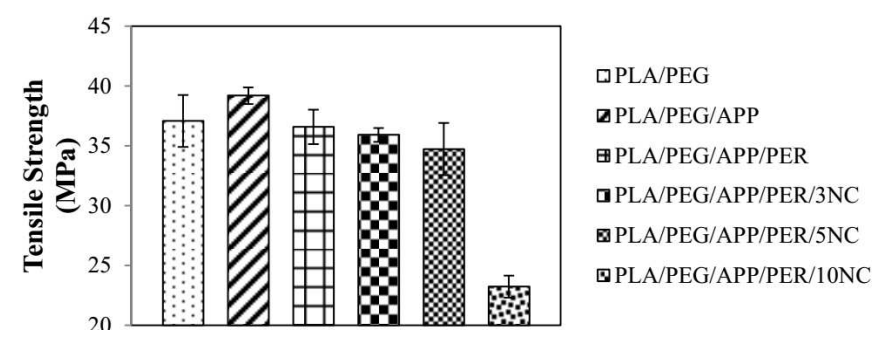

Fig. 1. Tensile strength values of prepared samples.

Figure 2 shows the strain at break values of the prepared samples. The highest strain at break value of $295 \%$ 


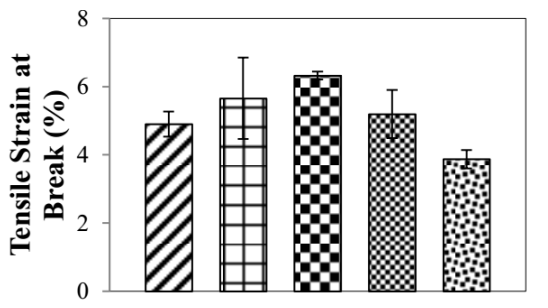

$\square \mathrm{PLA} / \mathrm{PEG} / \mathrm{APP}$ $\square$ PLA/PEG/APP/PER aLA/PEG/APP/PER/3NC (PLA/PEG/APP/PER/5NC $\square \mathrm{PLA} / \mathrm{PEG} / \mathrm{APP} / \mathrm{PER} / 10 \mathrm{NC}$

Fig. 2. Strain at break values of prepared samples.

was obtained in plasticized PLA. It was observed that the addition of APP, PER and nanoclay into the PLA/PEG resulted in a decrease in strain at break values.

\subsection{Thermal properties}

Thermal properties of pure PLA and of the prepared samples were investigated using DSC analysis and the summary of the results is given in Table II. While the addition of the PEG has decreased the glass transition temperature $(T \mathrm{~g})$ value of the PLA, as expected, APP, PER and nanoclay addition did not changed substantially this value. The melting temperature values $\left(T_{\mathrm{m}}\right)$ of the prepared samples were slightly changed. The degree of crystallinity $\left(X_{\mathrm{c}}\right)$ of the PLA/PEG/APP was decreased by the addition of the PER. The addition of the nanoclay to composites increased the crystallinity. Maximum crystallinity was measured as $14.1 \%$ in the sample, which contained $10 \%$ of nanoclay.

TABLE II

DSC results for prepared samples.

\begin{tabular}{c|c|c|c|c|c}
\hline \hline Samples & $T_{\mathrm{g}}$ & $T_{\mathrm{m}}$ & $\begin{array}{c}\Delta H_{m} \\
{[\mathrm{~J} / \mathrm{g}]}\end{array}$ & $\begin{array}{c}\Delta H_{c} \\
{[\mathrm{~J} / \mathrm{g}]}\end{array}$ & $\begin{array}{c}X_{\mathrm{c}} \\
\%\end{array}$ \\
\hline $\mathrm{PLA}$ & 60.57 & 151.67 & 28.2 & 22.0 & 6.7 \\
$\mathrm{PLA} / \mathrm{PEG}$ & 45.7 & 152.3 & 31.6 & 27.8 & 4.5 \\
$\mathrm{PLA} / \mathrm{PEG} / \mathrm{APP}$ & 44.1 & 151.7 & 24.9 & 17.0 & 10.0 \\
$\mathrm{PLA} / \mathrm{PEG} / \mathrm{APP} / \mathrm{PER}$ & 44.8 & 150.3 & 23.4 & 18.8 & 6.9 \\
$\mathrm{PLA} / \mathrm{PEG} / \mathrm{APP} / \mathrm{PER} / 3 \mathrm{NC}$ & 43.8 & 149.2 & 18.9 & 11.9 & 10.4 \\
$\mathrm{PLA} / \mathrm{PEG} / \mathrm{APP} / \mathrm{PER} / 5 \mathrm{NC}$ & 44.1 & 150.1 & 22.9 & 14.1 & 13.1 \\
$\mathrm{PLA} / \mathrm{PEG} / \mathrm{APP} / \mathrm{PER} /$ 10NC & 44.8 & 148.0 & 32.7 & 23.2 & 14.1
\end{tabular}

TABLE III

Results of thermogravimetric analysis of composites.

\begin{tabular}{|c|c|c|c|c|}
\hline \multirow{3}{*}{ Samples } & \multicolumn{3}{|c|}{$\begin{array}{c}\text { Decomposition temp. } \\
\text { in nitrogen }\end{array}$} & \multirow{3}{*}{$\begin{array}{c}\text { Char } \\
\text { residue } \\
\text { percentage } \\
\left(750^{\circ} \mathrm{C}\right) \\
{[\%]}\end{array}$} \\
\hline & $5 \%$ & $50 \%$ & $85 \%$ & \\
\hline & \multicolumn{3}{|c|}{$\begin{array}{c}\text { by weight of } \\
\text { decomposit. }\left[{ }^{\circ} \mathrm{C}\right]\end{array}$} & \\
\hline PLA/PEG & 335.00 & 366.99 & 383.15 & 0.00 \\
\hline $\mathrm{PLA} / \mathrm{PEG} / \mathrm{APP}$ & 321.44 & 359.15 & 511.27 & 10.97 \\
\hline PLA/PEG/APP/PER & 300.88 & 352.16 & 434.37 & 10.67 \\
\hline $\mathrm{PLA} / \mathrm{PEG} / \mathrm{APP} / \mathrm{PER} / 3 \mathrm{NC}$ & 302.34 & 349.75 & 440.36 & 13.02 \\
\hline $\mathrm{PLA} / \mathrm{PEG} / \mathrm{APP} / \mathrm{PER} / 5 \mathrm{NC}$ & 299.85 & 350.12 & 438.31 & 13.12 \\
\hline $\mathrm{PLA} / \mathrm{PEG} / \mathrm{APP} / \mathrm{PER} / 10 \mathrm{NC}$ & 296.93 & 350.50 & 620.66 & 13.12 \\
\hline
\end{tabular}

The thermal decomposition behaviour of samples was investigated using TGA. The TGA results for the samples were obtained in nitrogen atmosphere and were given in Table III. Pure PLA/PEG has completely degraded at around $430{ }^{\circ} \mathrm{C}$. Temperature corresponding to $5 \%$ of weight loss has shifted from $335^{\circ} \mathrm{C}$ to $296^{\circ} \mathrm{C}$ with the addition of the APP, PER and nanoclay to the plasticised PLA.

Addition of APP to PLA/PEG has caused formation of a significant amount of char residue (approximately 10 wt.\%). There is no significant difference of char residue percentage before and after PER incorporation at $800^{\circ} \mathrm{C}$. This result shows that $\mathrm{APP} / \mathrm{PER}$ intumescent system, in combination with PLA, has provided an increment of the flame resistance of PLA-based system.

It can be assumed that APP/PER interacts with matrix, catching the polymer fragments or degradation products of polymers in the intumescent structure [10]. Addition of nanoclay to PLA/PEG/APP/PER system caused no significant change in 5 wt. $\%$ decomposition temperature. Besides the changes of the weight loss, above $400{ }^{\circ} \mathrm{C}$ appear more stable clay layers. Addition of nanoclay to PLA-based system has increased char residue by $3 \%$. This behaviour can be explained by the barrier properties of clay layers [6].

\subsection{Flammability properties}

Combustion properties of samples were shown in Table IV. The flammability behaviour of composites in vertical position was examined by exposing to flame in UL-94 test. V2 classification was obtained for the PLA/PEG sample in the UL-94 test. On the other hand samples have shown the V-0 classifications. Higher LOI values indicate better flame resistance property. For PLA/PEG, LOI value was measured as 24 .

TABLE IV

UL-94 and LOI test results.

\begin{tabular}{c|c|c|c|c}
\hline \hline Samples & UL-94 & Dripping & $\begin{array}{c}\text { Ignition } \\
\text { of the } \\
\text { cotton }\end{array}$ & $\begin{array}{c}\text { LOI } \\
\left(\% \mathrm{O}_{2}\right)\end{array}$ \\
\hline PLA/PEG & V-2 & Yes & Yes & 24 \\
PLA/PEG/APP & V-0 & Yes & No & 31 \\
PLA/PEG/APP/PER & V-0 & Yes & No & 39 \\
PLA/PEG/APP/PER/3NC & V-0 & Yes & No & 33 \\
PLA/PEG/APP/PER/5NC & V-0 & Yes & No & 32 \\
PLA/PEG/APP/PER/10NC & V-0 & Yes & No & 29
\end{tabular}

The addition of APP increased the LOI value of the polymer systems and provided flame resistance (the limit length was not consumed). The LOI value of PLA/PEG/APP system was measured to be 31. PER addition to the system, has increased the LOI value up to 39 and the best LOI value was obtained with $\mathrm{PLA} / \mathrm{PEG} / \mathrm{APP} / \mathrm{PER}$.

These results show that the combination of APP and PER system has a synergetic effect on flame resistance. Nanoclay addition has decreased LOI value. 
The LOI value of 33 was obtained in composite samples containing $3 \%$ of nanoclay, the limit length was not consumed. LOI values of $\mathrm{PLA} / \mathrm{PEG} / \mathrm{APP} / \mathrm{PER} / 5 \mathrm{NC}$ and $\mathrm{PLA} / \mathrm{PEG} / \mathrm{APP} / \mathrm{PER} / 10 \mathrm{NC}$ were obtained as 32 and 29 , respectively, at this values the limit length was consumed.

\subsection{Scanning electron microscopy}

Scanning electron microscopy (SEM) analysis was employed to investigate the morphology of the PLA/PEG blend and of the prepared composites. SEM micrographs of the samples were given in Fig. 3a-g. Phase separation was not observed in plasticized PLA. Plasticized PLA has shown plastic deformation during tensile tests.

In PLA/PEG/APP system, APP shows hexagonal prism structure and voids were observed. Besides this, if tensile test results are considered, toughness of APP has contributed to the increase in tensile strength and to the decrease in elongation at break values of samples. Decreasing elongation values were ascribed to a more brittle behaviour.

Introduction of PER has increased the voids, as expected (Fig. 3c). Tensile strength values were slightly reduced, compared to PLA/PEG/APP, because of voids. The APP and PER addition into this system resulted in improved flame retardancy because of the increase of voids in the system.

The heterogeneous dispersion was observed for samples including nanoclay. Due to this heterogeneous dispersion, tensile strength of these samples was decreased, compared to PLA/PEG/APP/PER sample. In addition to this, agglomeration was observed at higher nanoclay contents. Agglomerations of nanoclay resulted in brittle formations, because of the stiff nature of nanoclay.
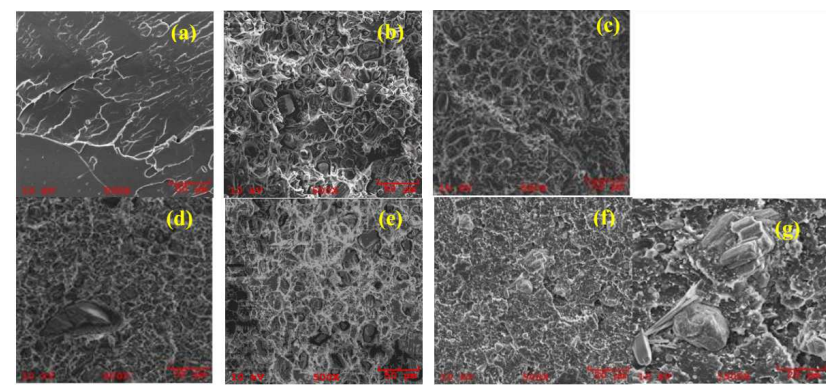

Fig. 3. SEM images of (a) PLA/PEG, (b) $\mathrm{PLA} / \mathrm{PEG} / \mathrm{APP}, \quad$ (c) $\mathrm{PLA} / \mathrm{PEG} / \mathrm{APP} / \mathrm{PER}$ (d) $\mathrm{PLA} / \mathrm{PEG} / \mathrm{APP} / \mathrm{PER} / 3 \mathrm{NC}, \quad$ (e) PLA $/ \mathrm{PEG} /$ $\mathrm{APP} / \mathrm{PER} / 5 \mathrm{NC}$, (f) $\mathrm{PLA} / \mathrm{PEG} / \mathrm{APP} / \mathrm{PER} / 10 \mathrm{NC}$, (g) PLA/PEG/APP/PER/10NC $(1500 \times)$.

\section{Conclusions}

The effects of an intumescent system, consisting of ammonium polyphosphate, as a flame retardant additive, pentaerythritol, as a carbonic agent and nanoclay, as a synergistic agent of the flame retardancy properties, of plasticized poly(lactic acid) were investigated. The maximum tensile strength value of 39.19 MPa was obtained for PLA/PEG/APP sample. Besides, tensile strength values of the samples have decreased with the addition of nanoclay and carbonic agent. The LOI value of PLA/PEG/APP system was measured to be 31. PER loading has increased the LOI value up to 39 and the best LOI value was obtained with $\mathrm{PLA} / \mathrm{PEG} / \mathrm{APP} / \mathrm{PER}$. Increasing nanoclay loading level has decreased the LOI value.

\section{Acknowledgments}

Authors thank Miss Isıl Üner and Merve Erkoç for experimental assistance in preparing the compounds.

\section{References}

[1] S. Solarski, M. Ferreira, E. Devaux, Polymer 46, 11187 (2005).

[2] D. Turan, H. Sirin, G. Ozkoc, J. Appl. Pol. Sci. 121, 1067 (2011).

[3] F. Shukor, A. Hassan, Md. S. Islam, M. Mokhtar, M. Hasan, Mater. Design 54, 425 (2014).

[4] K. Kimura, Y. Horikoshi, Fujitsu Sci. Tech. J. 41, 173 (2005).

[5] F. Akarslan, Acta Phys. Pol. A 128, B-403 (2015).

[6] X.Q. Su, J. Tao, Y.W. Yi, Y.H. Cui, Q. Wang, Synergistic Flame Retardant Effect of Attapulgite on PP/APP/PER Compersites, in: 18th Int. Conf. on Comp. Mat., Jeju Island, Korea 2011.

[7] C.H. Ke, J. Li, K.Y. Fang, Q.L. Zhu, J. Zhu, Q. Yan, Y.Z. Wang, Polym. Degrad. Stab. 95, 763 (2010).

[8] M. Le Bras, S. Bourbigot, Y.L. Tallec, J. Laureyns, Polym. Degrad. Stabil. 56, 11 (1997).

[9] S. Bourbigot, M. Le Bras, S. Duquesne, M. Rochery, Macromol. Mater. Eng. 289, 499 (2004).

[10] C. Reti, M. Casetta, S. Duquesne, S. Bourbigot, R. Delobel, Pol. Adv. Tech. 19, 628 (2008).

[11] P. Lv, Z.Z. Wang, K.L. Hu, W.C. Fan, Polym. Degrad. Stab. 90, 523 (2005).

[12] H. Zhu, Q. Zhu, J. Li, K. Tao, L. Xue, Q. Yan, Polym. Degrad. Stab. 96, 183 (2011).

[13] M. Pluta, A. Galeski, M. Alexandre, M.A. Paul, J. Appl. Polym. Sci. 86, 1497 (2002).

[14] C.D. Migliaresi, D. Cohn, A. De Lollis, L. Fambri, J. Appl. Polym. Sci. 43, 83 (1991). 